\title{
Spatial patterns of frequency and duration for persistent near-normal climatic events in the contiguous United States
}

\author{
Peter T. Soulé \\ Department of Geography, The University of Alabama, Tuscaloosa, Alabama 35487-0322, USA
}

\begin{abstract}
In contrast to most extreme climatic events, little is known about how often and for how long the weather or climate is within close range of normal. The primary purpose of this paper is to examine the spatial patterns of persistent near-normal climatic event frequency and duration in the contiguous United States. Data examined are standardized mean monthly temperatures (TEMPZ), standardized total monthly precipitation (PREZ), and monthly values of the Palmer Drought Severity Index (PDSI) for all climatic divisions in the contiguous United States for the period 1958-1989. Nearnormal climate events are defined as periods of at least 3 or 6 consecutive months with index (PDSI, TEMPZ, PREZ) values within +1 to -1 standard deviations. Isoline maps based on 6 -month minimum duration events show conspicuous spatial pattens for temperature and precipitation, with core areas of maximum frequency in the Great Plains for the number of consecutive months with TEMPZ within $\pm 1 \sigma$ and in the extreme west/southwest for the number of consecutive month with PREZ within $\pm 1 \sigma$. For near-normal events defined using the PDSI, there are generally more recorded events in the eastern United States and less in the west. The average duration maps indicate a low degree of spatial variability for near-normal temperature and moisture events. Distinct patterns are found on the precipitation maps, where the average length is comparatively large in the extreme western/southwestern United States.
\end{abstract}

\section{INTRODUCTION}

Sustained deviations from normal climatic conditions can create serious problems for plants, animals, and human activities. Because of this, the study of climatic extremes and extreme climatic events is an integral part of geographical and climatological literature. Various quantitative measures and numerical indices have been devised to monitor these climatic extremes. Examples include, among others, the use of statistical recurrence intervals for examining flooding frequency (Kite 1977), the Palmer Drought Severity Index (Palmer 1965) for droughts and wet spells, indices of wind chill for combinations of extreme cold and wind (e.g. Siple $\&$ Passel 1945), heat stress or comfort indices for combinations of high temperature and humidity (e.g. Thom 1959. Terjung 1966) and heating/cooling degree days to monitor energy demand at high or low temperature (e.g. Suckling \& Stackhouse 1983).
Geographers and climatologists are also engaged in the study of climatic normals. All introductory physical geography and climate textbooks deal with the topic of climatic normals in one way or another, and the interest in climatic normals persists all the way to state-of-the-art Global Circulation Models, which help to determine how far we might deviate from climatic normals in the wake of increasing outputs of greenhouse gases. To identify significant deviations from normal, the normal condition of weather and climate must be determined. Lamb \& Changnon (1981), Guttman \& Plantico (1987), Katz (1988), and Kunkel (1988) provide excellent discussions of the concept and determination of climatic normals. The consensus is that no one climatic normal (e.g. a $30 \mathrm{yr}$ normal) is best for all purposes. Since climate changes through time, climatic normals should be updated at regular intervals.

In contrast to most extreme climatic events, little is 
known about how often, and for how long, the weather or climate is within close range of normal. Although monthly or seasonal rankings of temperature and precipitation or drought index information can be used to identify periods of near-normal climatic conditions, publications such as the Climate Analysis Center's Weekly Climate Bulletin tend to focus on climatic extremes (e.g. see Climate Analysis Center 1992). Spatial patterns of extended periods of average or normal weather have not been thoroughly pursued in the climatic literature. Popular publications such as the Places Rated Almanac (Boyer \& Savageau 1985) have developed climatic ranking schemes, but these are based largely on monthly normals of temperature and humidity. Stations which normally record temperatures and humidities outside acceptable ranges for human comfort are typically poorly ranked.

Rather than compare regions or locations (via rankings) based upon whether they typically experience temperatures and relative humidities within arbitrary 'comfortable' ranges, this study examines regional differences in the persistence of average or normal weather based upon the location's climatic normals. The question (and basis for regional comparison) then becomes which area experiences the most persistent spells of near-normal weather, whatever the local normal may be. Thus, the primary purpose of this paper is to examine the spatial patterns of persistent near-normal climatic events in the contiguous United States. Both the frequency and duration of these events are examined.

\section{DATA AND METHODS}

Data for this study include standardized monthly values of average temperature and total precipitation, and monthly values of the Palmer Drought Severity Index (PDSI) for the 344 climatic divisions in the contiguous United States (Fig. 1) for the period 1959-1988 (Palmer 1965). All data are from the National Climatic Data Center's magnetic tape file TD9640 (NCDC 1989). The PDSI has been the most frequently used measure of regional moisture severity in United States climatological studies within the last $20 \mathrm{yr}$. The PDSI is water-balance-based, matching demand for moisture (evapotranspiration) with supply (precipitation). The index is designed so that values near zero represent normal moisture conditions, negative values represent moisture conditions below normal (drought), and positive values moisture conditions above normal (wet spells). The PDSI has an intermediate rate of response to changes in supply and demand of moisture and is described as a measure of meteorological or average moisture conditions (Palmer 1965). Qualitative severity labels attached to various ranges of the PDSI are summarized in Table 1. Detailed descriptions of the procedures used to calculate the PDSI are provided by Alley (1984) and Karl (1986)

Although it has many definitions, the term 'drought' is commonly used in reference to a period of moisture deficiency that deviates from climatic normals for the location or region under investigation (Palmer 1965). Diaz (1983) introduced a definition scheme for drought events based on multi-month persistence of drought

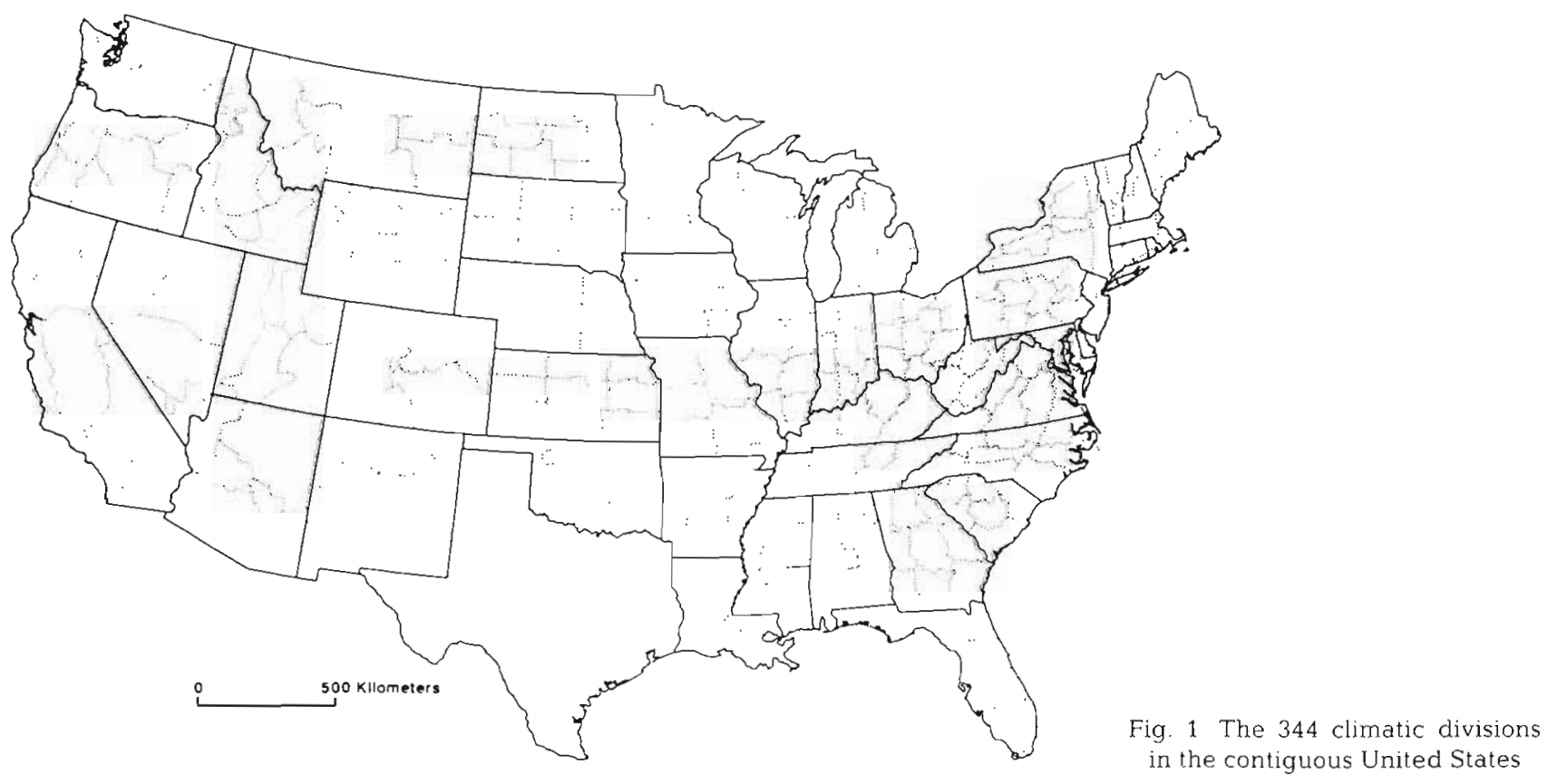


Table 1. Severity classes for the PDSI (after Palmer 1965, p. 28)

\begin{tabular}{|c|c|c|}
\hline $\begin{array}{l}\text { Approximate } \\
\text { cumulative } \\
\text { frequency }(\%)\end{array}$ & PDSI value & Severity class \\
\hline$\geq 96$ & $\geq 4.00$ & Extemely wet \\
\hline $91-96$ & 3.00 to 3.99 & Very wet \\
\hline $67-90$ & $\begin{array}{l}2.00 \text { to } 2.99 \\
1.00 \text { to } 1.99\end{array}$ & $\begin{array}{l}\text { Moderately wet } \\
\text { Slightly wet }\end{array}$ \\
\hline $37-66$ & $\begin{array}{r}0.50 \text { to } 0.99 \\
0.49 \text { to }-0.49 \\
-0.50 \text { to }-0.99\end{array}$ & $\begin{array}{l}\text { Incipient wet spel } \\
\text { Near normal } \\
\text { Incipient drought }\end{array}$ \\
\hline $11-36$ & $\begin{array}{l}-1.00 \text { to }-1.99 \\
-2.00 \text { to }-2.99\end{array}$ & $\begin{array}{l}\text { Mild drought } \\
\text { Moderate drought }\end{array}$ \\
\hline $5-10$ & -3.00 to -3.99 & Severe drought \\
\hline$<5$ & $\leq-4.00$ & Extreme drought \\
\hline
\end{tabular}

conditions. He considered a string of 3 or more consecutive months with PDSI values $\leq-2.0$ (moderate drought) to be a drought event, with a series of 6 or more months a major drought event. To identify nearnormal climatic events, the 3 and 6 month minimum durations used by Diaz (1983) to identify droughts and wet spells are applied in the current study. Nearnormal climatic events for temperature and precipitation are defined as any span of 3 or more consecutive months with standardized scores of temperature (precipitation) within a range of +1 to -1 standard deviations. Similarly, 'major' near-normal climatic events for temperature and precipitation are defined as any span of 6 or more consecutive months with standardized scores between +1 and -1 . By using a minimum duration equivalent to one season to identify near-normal climatic events, an assessment of climatic persistence is built into this study.

According to Palmer's quantitative labels (see Table 1), the PDSI is 'near-normal' in the range +0.49 to -0.49 . However, the frequency distribution of the PDSI for most climatic divisions is bi-modal, with peaks around +1 and -1 (Alley 1984). Because of this bimodal distribution, use of the 'near-normal' category proved to be unsatisfactory for identifying near-normal moisture events. Since many climatic divisions recorded zero near-normal moisture events during the $30 \mathrm{yr}$ study period when using the 'near-normal' category, the definition was relaxed so that 3 or more consecutive months with PDSI values between +1 (incipient wet spell) and -1 (incipient drought) identifies a nearnormal moisture event, 6 or more consecutive months a major event.

Since monthly data are used, there is no control for intra-monthly variability. Clearly it is possible for a given month to have a mean temperature near normal, despite recording a mix of colder-than-average and warmer-than-average temperatures. Similarly, a given climatic division could record near-normal monthly precipitation, with all the precipitation falling on the last day of the month. Despite these possible limitations, the data set used provides excellent spatial resolution, is corrected for biases (Karl et al. 1986), and is well suited for the purpose of examining continentalscale spatial patterns. Calculations of near-normal climatic event frequency and average duration were made for 6 scenarios: standardized average monthly temperatures (TEMPZ), standardized total monthly precipitation (PREZ), and PDSI 3-month and 6-month events. Values of frequency of near-normal events and average duration of near-normal conditions were then plotted at the climatic division centroids and interpolated using the Kriging algorithm of Golden Software's SURFER program (Golden Software 1989). Isoline maps are used to show the patterns of frequency and average duration across the contiguous United States.

\section{RESULTS}

A summary of near-normal climatic event characteristics across all 344 climatic divisions shows strong similarities between temperature and precipitation (Table 2). The frequency of both TEMPZ and PREZ 3-month near-normal events is slightly more than 1 per year, with a small range in total number of events across the contiguous United States. Near-normal (3month) moisture events (PDSI) occur considerably less frequently, and there is a greater range and variability in moisture events across the 344 climatic divisions.

The summary statistics for major (6-month minimum duration) near-normal climatic events show that both temperature and precipitation near-normals have the propensity for long-term persistence in the contiguous United States, with the average length of these events spanning the equivalent of nearly 3 seasons (Table 2 ). The same tendency for persistence also exists for nearnormal moisture conditions when they occur; however, the mean frequency of near-normal moisture conditions is considerably less than for near-normal major temperature and precipitation events. The frequency of 6-month minimum duration events decreases proportionally for the 3 measures, with slightly over onethird as many recorded events in each case. In comparison to 3 -month minimum duration events, relative variability around the mean increases for 6-month minimum duration event frequency for all 3 measures, and for event duration for temperature and moisture.

The frequency of near-normal temperature events ranges from $<30$ in the Great Basin to $>40$ in the lower Mississippi Valley and northern New England (Fig. 2A). 
Table 2. Summary of near-normal climatic event characteristics for all 344 climatic divisions (1959 to 1988)

\begin{tabular}{|c|c|c|c|}
\hline Event & Mean & $\mathrm{SD}$ & Range \\
\hline \multicolumn{4}{|l|}{ TEMPZ, 3-month } \\
\hline No. of events & 36.4 & 2.9 & $28-45$ \\
\hline Average length $(\mathrm{mo})$ & 5.3 & 0.4 & $4.3-6.5$ \\
\hline \multicolumn{4}{|l|}{ PREZ, 3-month } \\
\hline No. of events & 37.7 & 3.3 & $30-47$ \\
\hline Average length (mo) & 5.4 & 0.6 & $4.3-9.6$ \\
\hline \multicolumn{4}{|l|}{ PDSI, 3-month } \\
\hline No. of events & 14.2 & 3.7 & $4-26$ \\
\hline Average length (mo) & 5.3 & 0.8 & $3.8-9.0$ \\
\hline \multicolumn{4}{|l|}{ TEMPZ, 6-month } \\
\hline No of events & 13.0 & 2.6 & $5-20$ \\
\hline Average length (mo) & 8.1 & 0.8 & $6.6-11.8$ \\
\hline \multicolumn{4}{|l|}{ PREZ, 6-month } \\
\hline No. of events & 13.3 & 2.7 & $4-22$ \\
\hline Average length (mo) & 8.4 & 0.9 & $6.7-31.4$ \\
\hline \multicolumn{4}{|l|}{ PDSI, 6-month } \\
\hline No. of events & 4.8 & 2.1 & $0^{c t}-11$ \\
\hline Average length (mo) & 8.3 & 1.5 & $6.0^{-1}-15.0$ \\
\hline \multicolumn{4}{|c|}{$\begin{array}{l}\text { A For the one climatic division that recorded } 0 \text { major } \\
\text { moisture events, the average length was set to } 6 \text { mo for } \\
\text { mapping purposes }\end{array}$} \\
\hline
\end{tabular}

The overall spatial patterns are complex, with conspicuous intra-regional variability despite the low overall variability around the mean. The complexity of the frequency patterns makes climatological interpretation difficult. Perhaps the most interesting patterns are found in the Pacific coastal region, where generally lower numbers of events are recorded. The year-round oceanic influences and dominance of stable high pressure and associated lack of precipitation during the warm season seem to make this region ideal for consistent thermal conditions at the surface. The lack of variability in the average duration of near-normal temperature events is clearly shown in the resulting spatial patterns (Fig. 2B).

Patterns of frequency for near-normal precipitation events are also highly variable both within and between regions (Fig. 2C). However, there is a clear pattern to average event duration, with the longest mean length in the extreme southwest and southern Pacific coastal regions (Fig. 2D). The general lack of warm-season precipitation in these dry-summer temperate climates probably makes it easier to string together multiple months of near-normal conditions. The fact that long duration combines with comparably low event frequency in this region is not surprising, because as duration increases the opportunity for large numbers of events should decrease. Spatial pattern correlations between event frequency and duration generally support this hypothesis (Table 3), with weak to moderate negative relationships in 5 of the 6 scenarios examined. An additional check of this hypothesis was performed by comparing the frequency and duration of near-normal precipitation events based on a 1-month minimum duration definition. A spatial pattern correlation revealed a strong relationship between frequency and duration $(r=-0.94)$, with the arid southwest and Pacific coastal regions recording a low number of long-duration events.

For near-normal moisture events, there is a subtle east-west dichotomy (Fig. 2E, F). Most climatic divisions east of the Mississippi recorded 14 or more events, most divisions west of the Rocky Mountains less than 14 events, and the central states had a mixed pattern. Average length was generally less than $5.5 \mathrm{mo}$ east of the Mississippi, with pockets of increasing frequency in the southwestern plateau region (New Mexico), the north-central intermountain region, and the Pacific coastal region. Frequency seems to be tied to mean annual precipitation. The core area of minimum frequency surrounds the Great Basin, where most divisions have a mean annual precipitation of $<50 \mathrm{~cm} \mathrm{yr}^{-1}$. The low annual and monthly precipitation probably makes it difficult to string together successive months of near-normal moisture, since small amounts of precipitation (non-precipitation) would cause the PDSI to move away from normal, especially if coupled with above-normal (below-normal) temperatures. However, there are climatic divisions with an equally low number of events in regions with ample yearly precipitation (>130 cm), such as the lower Mississippi Valley.

Analyses based on 6-month minimum duration events produced more distinct spatial patterns. For temperature, the dominant map features are the core area of maximum frequency centered in the central Great Plains (Fig. 3A), and the core area of maximum duration centered in the southern Great Plains (Fig. 3B). Normal temperatures can most easily be related to periods of zonal flow, temperature extremes to periods of meridional low. Although it is unrealistic to assume persistent zonal flow for 6 or more months, the high frequency of normal temperature events to the lee of the Rocky Mountains is likely related to the mean longwave pattern. Dynamic forcing typically leads to ridging over the Rocky Mountains and troughing to the east (Harmon 1991). The Great Plains are in somewhat of a transition zone where mean zonal low, and thus normal temperatures, should be favored. However, higher frequencies also exist in the lower Mississippi Valley and portions of the southeastern states, areas where cyclogenesis is typically associated with accentuated meridional flow. Spatial patterns of event frequency also may be related to air mass dominance. Although not a perfect pattern (evidenced by the lower Mississippi Valley and extreme 


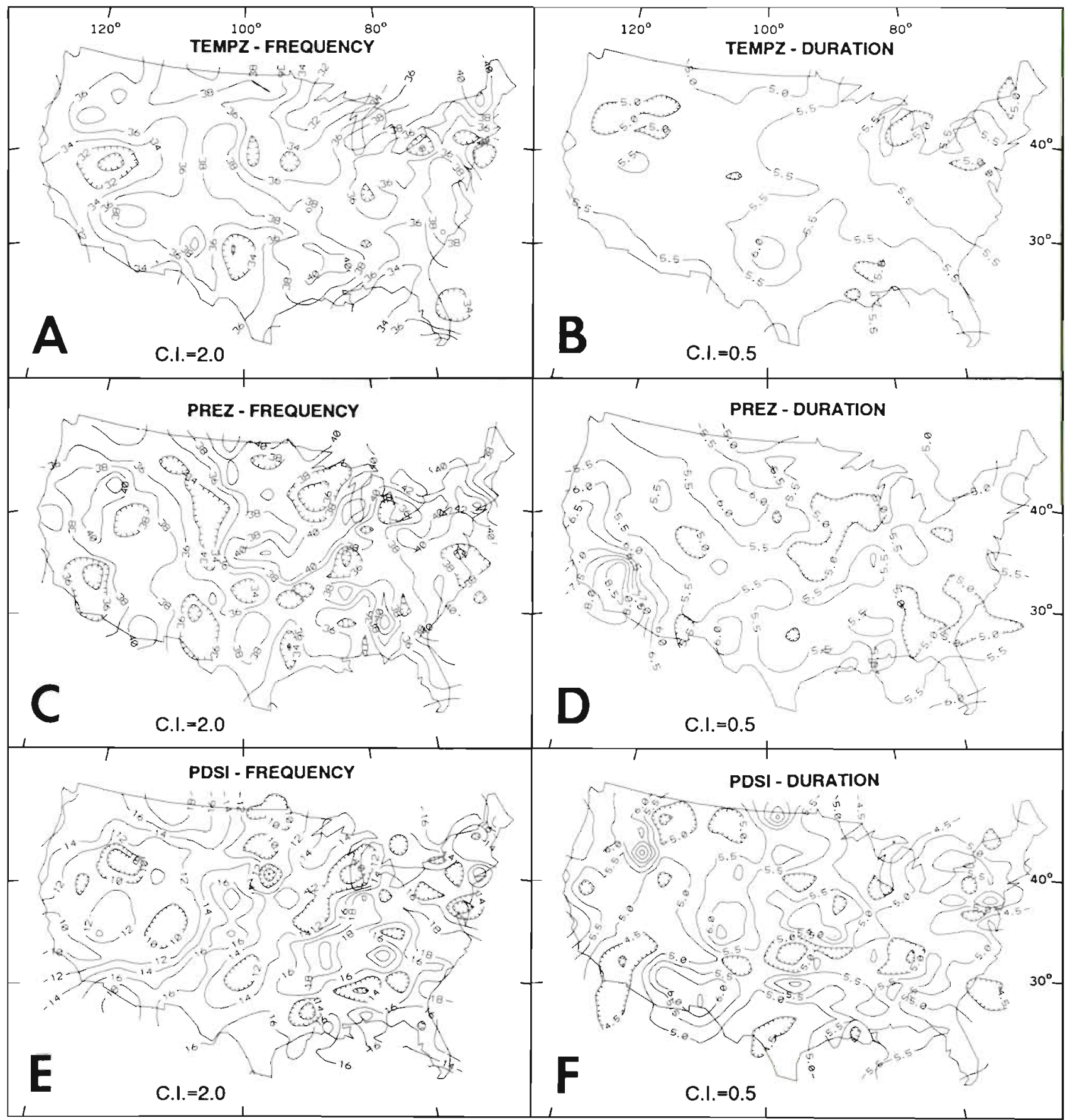

Fig. 2. Isoline maps showing the total number of near-normal climatic events ( 3 -month minimum duration) during the $30 \mathrm{yr}$ study period for (A) temperature (TEMPZ), (C) precipitation (PREZ), and (E) moisture (PDSI), and the average duration (in months) of these events for $(B)$ temperature, $(D)$ precipitation, and $(F)$ moisture. C.I. = contour interval

northern Great Plains), there does seem to be a relationship between proximity to moisture sources and event frequency. The same relationship does not hold for event duration.

For precipitation, there is a large shift from the 3 month pattern (Figs. 2C, D \& 3C, D). The most notice- able shift in the spatial pattern is in the extreme west (California and Arizona). This area now has both the greatest frequency and duration of near-normal precipitation events. The strength of this relationship in the extreme west clearly influences the spatial pattern correlation for the entire United States, as there is now 
Table 3. Simple pattern correlations between normal event frequency and duration ( $\mathrm{n}=344$ in all cases)

\begin{tabular}{|lr|}
\hline Events & r-value (significance) \\
\hline TEMPZ, 3-month & $-0.63(0.0001)$ \\
PREZ, 3-month & $-0.54(0.0001)$ \\
PDSI, 3-month & $-0.19(0.0005)$ \\
TEMPZ, 6-month & $-0.45(0.0001)$ \\
PREZ, 6-month & $0.11(0.0467)$ \\
PDSI, 6-month & $-0.11(0.0462)$ \\
\hline
\end{tabular}

a weak positive relationship between event frequency and duration (Table 3). The high average duration is probably linked to the extremely low annual precipitation in the southwest and southern Pacific coastal areas. The high frequency pattern matches up closely with the dry-summer subtropical desert climates of the western United States. Just as the low volume of precipitation normally received between May and October makes it difficult to ameliorate or end any droughts that develop during the winter or spring in this region (Karl et al. 1987), this also may give this region a running start for recording more longduration near-normal precipitation events than other regions of the United States. Topographic influences may help accentuate the pattern. The region of maximum frequency is generally confined west of the Sierra Nevadas, and the northeastward bulge of the 20 -event isoline correlates with the southern terminus of this mountain range and the general location of the Mojave Desert. Frequency is also reduced throughout the Rocky Mountains, suggesting that climatic complexity due to orographic influences makes it difficult for near-normal conditions to persist for extended periods of time.

Perhaps even more interesting is the complex pattern of precipitation event frequency (Fig. 3C) in the south to north-central Great Plains. This area has a propensity for summertime dominance of anticyclonic flow, which produces both droughts and heat waves (Namias 1983). The persistence of drought conditions in this region is well documented (Karl \& Koscielny 1982, Walsh et al. 1982, Diaz 1983, Karl et al. 1987. Soulé 1992a). Since droughts are persistent in the Great Plains, with some climatic divisions recording drought conditions for over 10 consecutive years (Soule 1992a), the probability of recording large numbers of near-normal precipitation events is reduced. In comparison to the southern Pacific coastal region there are fewer events of shorter duration. However, there is considerable intra-regional variability, which is maximized in the central Great Plains. Climatic divisions in southeast Kansas record fewer than 8 events, and divisions in northwest Kansas record more than 16 events.
Although precipitation is the dominant in the derivation of the PDSI, the PDSI and PREZ are not strongly correlated with each other. The overall correlation between the 2 indices is around 0.46, with even weaker relationships with increasing aridity (Soulé 1992b). Clearly the PDSI and PREZ spatial patterns for major near-normal events are different (Fig. $3 \mathrm{C}$ to $\mathrm{F}$ ). For the PDSI, low frequency is somewhat homogeneous throughout the west, roughly centered on the Great Basin and western Rocky Mountains. This conforms to the 3-month minimum duration moisture patterns (Fig. 2E). The greatest frequency of near-normal events is found in the west-central Great Plains (central high plains). The slightly higher frequency in this region is interesting, as this area has been shown to have the greatest persistence of droughts (and wet spells) in the United States (Karl 1983), but not the greatest frequency of droughts (Soulé 1992a).

Spatial patterns of near-normal moisture event duration are complex (Fig. 3F), with both intra- and inter-regional ranges of 4 mo or more. No generalizations between the type of climatic regime (e.g. arid, humid) and propensity for longer or shorter events can be drawn. For example, in the arid southwest (Arizona and New Mexico) average event durations range from $<7$ to $>11 \mathrm{mo}$, and in the humid southeast the range is from $<8$ to $>12 \mathrm{mo}$.

\section{SUMMARY AND CONCLUSIONS}

The combination of high event frequency, low overall variability around the mean, and substantial intra-regional variability makes the 3 -month minimum duration patterns of near-normal event frequency for temperature and precipitation difficult to interpret. Multiple areas of high and low event frequency are found across the United States, suggesting that the controlling climatic processes are either stochastic in nature or are operating at largely the sub-meso scale. Three-month patterns for the PDSI also exhibit considerable intra-regional variability, but do show an east-west dichotomy with a low frequency core in the arid western United States (centered on the Great Basin) and generally higher frequencies east of the Mississippi River.

Expanding the persistence of near-nomal climatic events to a 6-month minimum resulted in more conspicuous spatial patterns for temperature and precipitation. Using 6-month patterns, core areas of maximum frequency of near-normal events are evident in the Great Plains for TEMPZ and in the extreme west/ southwest for PREZ. Circumstantially, the high frequency of temperature events in the interior portions of the United States suggests a relationship with the 


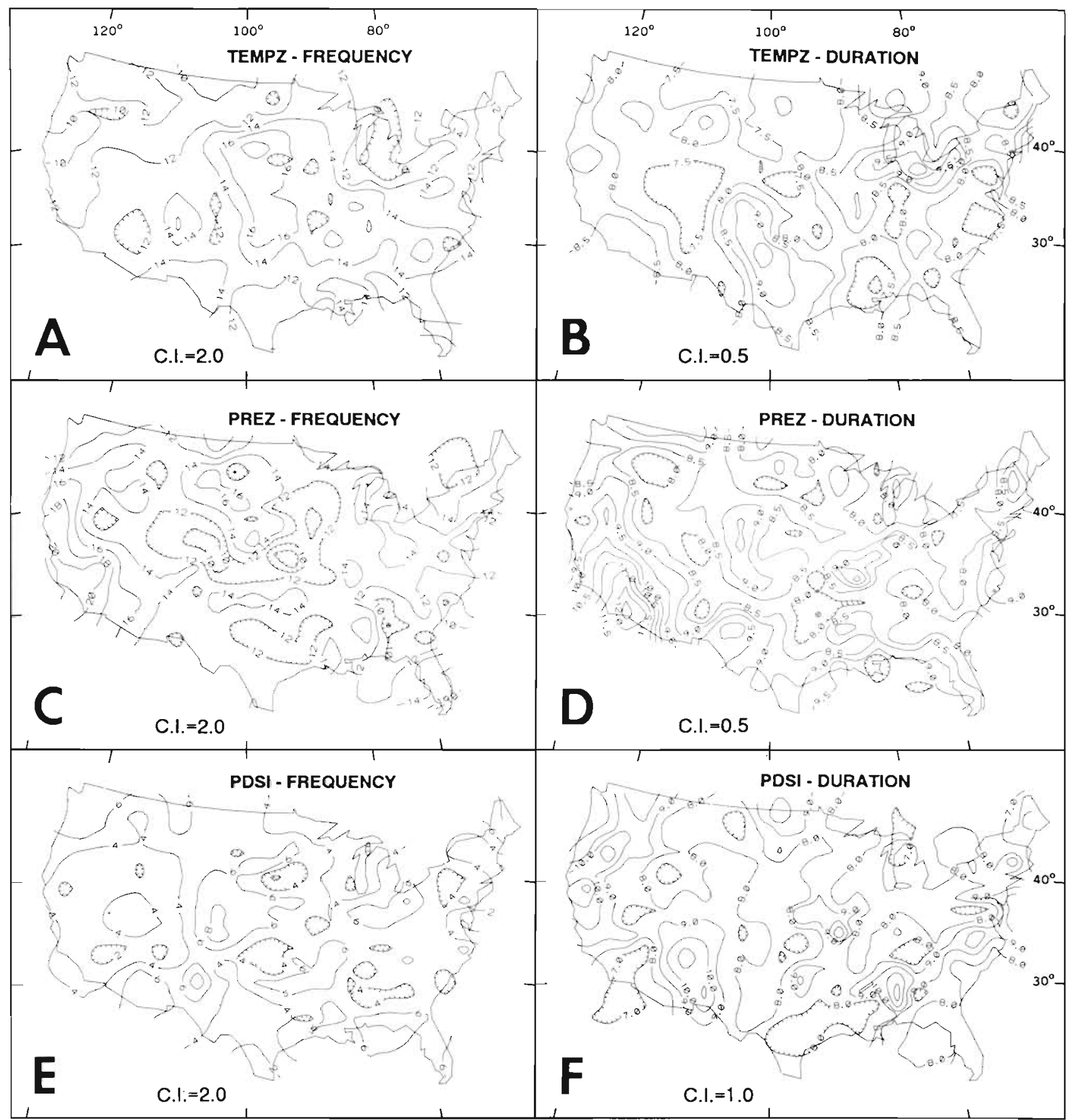

Fig. 3. As in Fig. 2, except for major (6-month minimum duration) near-normal climatic events

proximity of moisture sources. Other controlling hypotheses could be proposed; for example, the interior United States is frequently the contact zone among Arctic, Pacific, and Tropical airstreams (Bryson \& Hare 1974). Cause and effect relationships would be difficult to substantiate, but perhaps these air mass interactions serve to moderate temperatures over monthly time scales
The controlling mechanism for the high frequency of major precipitation events in the Pacific coastal region appears to be straightforward. On average, this region has the most stable surface conditions in the contiguous United States, influenced by the eastern side of the Pacific sub-tropical high and cold ocean currents. In Los Angeles, warm-season precipitation is barely measurable, averaging $<5 \mathrm{~mm} \mathrm{mo}^{-1}$ from May to 
September (Lydolph 1985, p. 246). Significant deviations from normal atmospheric flow patterns are needed to disrupt the warm-season aridity, and if these do not occur it would be easy to string together several months of near-normal precipitation. The converse of the low mean precipitation in the warm season is that a minor rainfall event, one that is statistically significant but realistically unimportant, could cause the index (PREZ) to move out of the near-normal range.

Overall, there was extremely low variability around the mean or average duration of near-normal events (Table 2). Spatial patterns are either very subdued (e.g. Fig. 2B), or exhibit a high degree of intra-regional variability (e.g. Fig. 3F) that makes them difficult to interpret in terms of possible controlling climatic conditions. However, noteworthy patterns were shown for precipitation. Near-normal precipitation events are clearly more persistent in the extreme west/southwest (California and Arizona) than in any other region of the United States. Near-normal precipitation events in the extreme west/southwest last, on average, up to a season $(3$ to $4 \mathrm{mo}$ ) longer than they do in other regions of the United States. The basic hypothesis for the high frequency of major near-normal precipitation events in this region, extreme stability and a lack of measurable mean warm-season precipitation, also can be applied to help explain the persistence patterns.

This study has approached the topic of climatic normality from the perspective of persistence or 'runs' of near-normal conditions. The importance of near-normal conditions is perhaps overlooked in climatology, probably because natural systems and human activities are not climatically stressed during normal conditions. Climatic normality maintains the status quo; natural phenological processes operate on schedule, planting, maturation, and harvesting of crops are unimpeded, and hydrologic systems operate with regionally and seasonally appropriate volumes of water. We know of the human suffering and economic hardships caused by extreme climatic events such as droughts and floods. Perhaps it is equally important to understand just how often, and for how long, a given region can expect to experience no major deviations from climatic normals, and therefore no major climatically induced economic crises. Just as climatologists are concerned about whether there will be increasing variability in climatic extremes under doubling of carbon dioxide scenarios, they should also consider how the characteristics of near-nomal climatic events may be altered.

Acknowledgements. This project was funded by the University of Alabama Research Grants Committee (\#1525). I thank the University of Alabama Cartographic Research Laboratory for preparation of graphics, and the 3 anonymous reviewers for their useful comments.

\section{LITERATURE CITED}

Alley, W. M. (1984). The Palmer Drought Severity Index: limitations and assumptions. J. Climate appl. Meteorol. 23: $1100-1109$

Boyer, R., Savageau, D. (1985). Places Rated Almanac. Rand McNalley \& Company, Chicago

Bryson, R. A., Hare, F. K. (1974). Climates of North America. Elsevier Scientific Publishing Co., Amsterdam

Climate Analysis Center (1992). Annual climate summary: major climatic events and anomalies in the United States during 1991. Weekly Clim. Bull. 92 (2): 9-24

Diaz, H. F. (1983). Some aspects of major dry and wet periods in the contiguous United States, 1895-1981. J. Climate appl. Meteorol. 22: 3-16

Golden Software (1989). SURFER Information Manual. Golden Software, Inc., Golden, $\mathrm{CO}$

Guttman, N. B., Plantico, M. S. (1987). Climatic temperature normals. J. climate appl. Meteorol. 26: 1428-1435

Harmon, J. R. (1991). Synoptic climatology of the westerlies: process and patterns. Association of American Geographers, Washington, D.C.

Karl, T. R. (1983). Some spatial characteristics of drought duration in the United States. J. Climate appl. Meteorol. 22: $1356-1366$

Karl, T. R. (1986). The sensitivity of the PaImer Drought Severity Index and Palmer's Z-Index to their calibration coefficients including potential evapotranspiration J. Climate appl. Meteorol. 25: 77-86

Karl, T R., Koscielny, A. J (1982). Drought in the United States: 1895-1981. J. Climatology 2: 313-329

Karl, T R., Quinlan, F., Ezell, D. D. (1987). Drought termination and amelioration: its climatological probability. J. Climate appl. Meteorol. 26: 1198-1209

Karl, T R., Williams, C. N., Young, P. J., Wendland, W. M (1986). A model to estimate the time of observation bias associated with monthly mean maximum, minimum, and mean temperatures for the United States. J. Climate appl. Meteorol. 25: 145-160

Katz, R. W. (1988). Statistical inferences about climate variability. $J$. Climate 1: 1057-1064

Kite, G. W. (1977). Frequency and risk analyses in hydrology. Water Resources Publications, Fort Collins, Colorado

Kunkel, K. (1988). Climatic means and normals. State Climatologist 12: $23-27$

Lamb, P. J., Changnon, S. A. Jr (1981). On the best temperature and precipitation normals. The Illinois situation. J. appl. Meteorol. 20: 1383-1390

Lydolph, P. E. (1985). The climate of the earth. Rowman \& Allanheld, Totowa, NJ

Namias, J. (1983). Some causes of United States droughts. J. Climate appl. Meteorol. 22: 30-39

NCDC (National Climatic Data Center) (1989). Time Bias Corrected Divisional Temp-Precip-Drought Index: TD9640 Tape Documentation. National Climatic Data Center, Asheville, NC

Palmer, W. C. (1965). Meteorological drought. Res. Pap. No. 45. U.S. Weather Bureau, Washington, D.C.

Siple, P. A., Passel, C. F. (1945). Measurements of dry atmospheric cooling in subfreezing temperatures. Proc. Am. phil. Soc. 89: 177-199

Soulé, P. T. (1992a). Spatial patterns of drought frequency and duration in the contiguous USA based on multiple drought event definitions. Int. J. Climatology 12: 11-24

Soulé, P. I (1992b). Concurrent and lagged relationships among various drought indices in the United States. MAUSAM: Indian J. Meteorol., Hydro., Geoph. 43: 43-50 
Suckling, P. W., Stackhouse, L. L. (1983). Impact of climatic variability on residential electrical energy consumption in the eastern United States. Arch. Met. Geoph., Biocl., Ser. B 33: $219-227$

Terjung, W. H. (1966). Physiologic climates of the conterminous United States: a bioclimatic classification based on

Editor: V. Meentemeyer man. Annals Ass. Am. Geographers 56: 141-179

Thom, E. C. (1959). The Discomfort Index. Weatherwise 11 $57-60$

Walsh, J E., Richman, M. B., Allen, D. W. (1982). Spatial coherence of monthly precipitation in the United States. Mon. Weather. Rev. 110: 272-286

Manuscript first received: June 2, 1992

Revised version accepted: July 20,1992 